\title{
Assessing Reading Strategies of Engineering Students: Think Aloud Approach
}

\author{
George Mathew Nalliveettil ${ }^{1}$ \\ ${ }^{1}$ Department of English, Aljouf University, Saudi Arabia \\ Correspondence: George Mathew Nalliveettil, Department of English, Aljouf University, Saudi Arabia. E-mail: \\ ngeorgeresearch@gmail.com
}

Received: January 23, 2014 Accepted: February 25, 2014 Online Published: April 14, 2014

doi:10.5539/elt.v7n5p38 URL: http://dx.doi.org/10.5539/elt.v7n5p38

\begin{abstract}
Literacy in reading and understanding printed words is significant for all undergraduate students to succeed in their academic career. Developments in digital technology improved the quality of academic texts in terms of design, format and layout. Further, availability of academic related English language resources in electronic versions gave readers to access and read the content on computer screens or download a text to make a hard copy. These developments on the printed pages of English course books helped the readers to identify letters of English alphabet precisely. However, vocabulary and sentence structures presented in the text remained difficult to the ESL students. A study was conducted to assess the reading strategies of engineering students across the state of Andhra Pradesh, India. Subjects of the study were 52 students pursuing engineering education in the engineering colleges affiliated to Jawaharlal Nehru Technological University, India.

The primary source of data was obtained through think-aloud verbal probe. Findings of the study reveal that engineering students feel disappointed and frustrated when the content presented in the course is beyond their comprehension. This research paper presents qualitative data obtained through think-aloud verbal probe. Insights from the verbal reports on reading strategies presented in this paper give new directions to the teaching-learning of English in ESL undergraduate classrooms. Findings presented from the study are significant for English teachers, researchers and curriculum designers to develop quality reading materials for ESL classrooms.
\end{abstract}

Keywords: reading, process, text, think-aloud, engineering

\section{Introduction}

Innovations in science and technology across the world influenced most of the administrators, diplomats, businessmen, engineers, scientists and medical practitioners to use English as a common medium for interpersonal communication. The realisation of English as a global link language triggered universities imparting engineering education to introduce English as a subject of study at the undergraduate level. Most of the engineering institutions in India have introduced English as medium of instruction at the undergraduate level. English is a second language for most of the Indian students. However, in the context of globalization, the English language has gained world-wide recognition and most of the international journals and books on engineering are published in English. Undergraduate students have to refer to journals and other current periodicals to update their knowledge in the field of engineering and technology. This requires engineering students to have proficiency in the English language to understand, interpret and analyze the content related to their academics as well as other fields of knowledge. As the process of reading varies from one text type to another, the reading strategies or the mental or behavioural activities using which an individual tries to comprehend a text also have to be constantly manipulated and accommodated to the text type and reading purpose. The primary focus of reading instruction should therefore be on developing the reading abilities of engineering students in order to make them independent readers.

The subjects of this study were undergraduate students pursuing first year B. Tech in the engineering colleges affiliated to Jawaharlal Nehru Technological University (JNTU), India. The admission procedure to engineering colleges affiliated to JNTU is based on EAMCET (Engineering, Agricultural and Medical Common Entrance Test) rank, reservation policy and management quota and thus students from varied educational and linguistic backgrounds are admitted to the engineering courses. Since engineering colleges affiliated to JNTU are established across the state of Andhra Pradesh, the counselling procedure followed for admitting the students to 
first year B.Tech course takes longer and this limits the duration of the academic year to around 8 months. Engineering students have to read and understand the instructions given in the lab manuals which require an adequate reading proficiency in the English language. The internal as well as external exams have to be written in the English language and students have to read and understand the questions which again require reading skills. A lot of study in the engineering course is reading oriented and students have to understand content and concepts for success in academics. Since much study in engineering education is reading oriented, the present study chose reading strategies as a specific focus.

\section{Review of Related Literature}

Developments in the social and the scientific spheres have created awareness among the people to become literates in the English language and also apply scientific knowledge to practical affairs. This resulted in English reading skills getting more attention. In the mid 1970's reading was viewed as translating the printed words to spoken ones which also mean reading aloud. Vaezi (2006) says that like teaching methodology, reading theories have had their shifts and transitions. Vaezi further points out that traditional focus was on the printed form of a text. The cognitive view enhanced the role of background knowledge while the metacognitive view is based on the control and manipulation that a reader can have on the act of comprehending a text.

\subsection{Think-Aloud Verbal Probe}

In second language study, Hosenfeld (1977) used a think-aloud procedure to identify relations between certain types of reading strategies of successful and unsuccessful second language reading. Hosenfeld examined successful and unsuccessful readers to find out what types of cognitive operations they used to process written texts. According to Someren et al. (1994), think-aloud protocol provides rich information about how learners solve problems, the difficulties they encounter and to what extent and contexts they use certain strategies in a learning task. Singhal (2001) says think-aloud involve overt, verbal expressions of the normally covert mental processes readers engage in when constructing meaning from texts. She further points out that protocol analysis has been used to investigate the range of reading strategies and behaviours as subjects read, and to better understand the cognitive processes during reading. However Ericsson and Simon (1980) point out that memory failure can be a particularly serious problem for verbal-report data. They further say that reports taken at a great distance from processes they are intended to tap may reveal little about reading comprehension process and strategies used by the reader. According to Singhal (2001), considerable differences exist in the tendency to speak aloud. She says verbal facility of the reader and limited language skills may affect the outcome of the interviews. Singhal points out that even in instances in which cognitions are generally accessible and remembered, it is possible that students cannot verbalize their thoughts. Despite the criticisms of verbal report data, Ericsson and Simon (1993) and Garner (1987) opine that a great deal can be learned about the reading comprehension, process and the psychology of thinking by making subjects think aloud about definite problems. They say that when verbal-reports are collected complex, difficult, and novel tasks may provide more information than much-practiced simple tasks and further reduce the interval between processing and reporting. According to Thomposon et al. (2006), think-aloud technique is labour-intensive and the sample size involved in the research is necessarily small. They further point out that small numbers, however, do not indicate small data sets since the research process is intensive, small sample sizes can provide valid information. Nielson (1994) suggests that sample groups as small as five participants will yield sufficient information about problem solving behaviour. From the study conducted by Thomposon et al. (2006) the think aloud method appears to provide important information on test design issues. The study demonstrated that design issues can be detected in tests when students think out loud while they are solving problems. Thomposon et al. (2006) conclude that one method that was found to be particularly effective in their study was the think aloud method. Ericsson and Simon (1980) view that people are aware and can report about the components of high level mental processes, like the sequence of steps that leads to the solution of a problem. Their research findings indicate that people temporarily store these steps in their working memory and are aware of what they are holding in working memory. Since our research focuses on exploring reading strategies of engineering students in Andhra Pradesh, we felt think-aloud probe would be useful to elicit the mental processes or sequence of steps that students make while reading an academic related text.

\subsection{Information-Processing Skills in Reading}

Reading can be viewed both as product and as process. Product is the result of what students understand while process relates to the ways and means through which a reader could understand a text. Alderson and Urquhart (1984) say that a product view relates only to what the reader has understood from the text while a process view investigates how the reader may arrive at a particular interpretation. More often, the classroom teaching of 
reading gives importance to the product rather than the process. Ajideh (2003) points out that there is unpredictability and variation in product and knowing the product does not give much information about what actually happens when a reader interacts with a text. Since the process underlies the product, Ajideh says that concentrating on process in research and teaching can improve the reading ability of learners. The present study also intends to gain insights into the L2 reading process of engineering students. It was felt that an investigation into the reading process of students can give insights into the kind of strategies they use while reading. Investigating the reading process also gives information on the problems and the reading behaviours of students while reading a text. The prescribed English text (Learning English: A Communicative Approach) for the engineering students also give more importance to the product of reading. However, the language instructors should be aware that tasks and activities related to reading process can benefit the students in reading comprehension. In order to improve reading skills, undergraduate students should be trained to identify the elements that are general across different texts. Ajideh points out that an understanding of cognitive skills is important to distinguish the kind of processes that successful and unsuccessful learners use while reading a text. According to Schwartz (1984), information processing, therefore, is an interaction between bottom up and data driven processes that depend on the nature of the stimulus input and top down or conceptually driven processes that depend on information, strategies, and expectancies learned over time and stored in long-term memory. Taraban et al. (2004) point out that the metacognitive reader plans the reading task monitors whether a coherent representation of the text is being maintained, and adopts different processing strategies related to the goals and outcomes of ongoing reading. Paris and Winograd (1990) maintain that metacognition can promote academic learning and motivation. The idea is that the students can enhance their learning by becoming aware of their own thinking as they read, write and solve problems at college. Mokhtari and Reichard (2002) say that the teachers can promote awareness by informing students about motivational characteristics of thinking. According to them there are three strategy subscales or factors: Global Reading Strategies, Problem-Solving Strategies, and Support Reading Strategies.

\subsection{Global, Problem Solving and Support Reading Strategies}

Mandler (1998) says that strategies are knowledge of procedures, knowledge about how to do something-how to decode a word, comprehend a story better, and compose more completely and coherently and such knowledge contrasts with declarative knowledge, the knowledge of facts. Global strategies are generalized, intentional reading strategies aimed at setting the stage for the reading act (e.g., setting purpose for reading, making predictions). Problem- Solving strategies provide readers with action plans that allow them to navigate through the text skilfully. Such strategies are focused problem solving or repair strategies used when problems develop in understanding textual information (e.g., checks readers understanding on encountering conflicting information or rereading for better understanding). Support strategies provide the support mechanisms aimed at sustaining responses to reading (e.g., use of reference materials such as dictionaries and other support systems). Mokhtari and Reichard (2002) say that Global, Problem-Solving and Support strategies serve a useful function for some students who seem to invoke them as needed. The data analysis presented in this paper is based on Mokhtari and Reichard (2002) classification of reading strategies to Global, Support and Problem Solving strategies.

\section{Research Design}

The main aim of the present research is to gain insights into the reading process of engineering students. The primary focus of the study is to probe into cognitive and metacognitive processes of the engineering students while reading academic English texts. This study intends to find out the reading strategies of students while reading an English text. This study was conducted after the series of pilot studies.

\subsection{Procedure Followed in the Study}

A study was conducted in 11 engineering colleges across the state of Andhra Pradesh, India. English teachers of the respective engineering colleges helped to identify students from varied educational background. This was necessary to find out if the strategy choice varied according to their background. Each individual student was interviewed separately. Moreover, it was felt that individual student interviews would avoid any kind of influence from their classmates. Hence, we began our study with individual student interview using think-aloud verbal probe. In all the engineering colleges visited, the researcher requested for a separate room to conduct the interview. The interviews with the students were recorded in a tiny audio recorder. Regular classes were going on when the researcher visited the engineering colleges and the researcher could not avoid some amount of background noise that crept into the recordings. However, the background noise did not affect the clarity of the recordings. The researcher briefed the higher authorities as well as the students about the audio recording and sought their approval before the interview was recorded. Before the interview with the students, the researcher 
introduced himself and assured the students that recorded interviews would be used only for research purposes. Students were asked to read an academic related passage silently and the researcher did not set a time limit for their reading. Students were encouraged to read and understand the given passage. Students were asked to report to the researcher after reading the complete passage. The verbal interview was recorded in a tiny audio recorder. None of the fifty two students interviewed objected to the recording.

\subsection{Engineering Colleges}

Field study was conducted in engineering colleges affiliated to Jawaharlal Nehru Technological University (JNTU), India. All the engineering colleges affiliated to JNTU are governed by the educational policies of the All India Council of Technical Education (AICTE). AICTE believes that communication skills are as important as management and engineering skills. For this reason, the committee stresses that curriculum has to include courses on communication skills. English is a compulsory subject in the first year B.Tech. Moreover, students have to write all their examinations in English. Further, the medium of instruction in engineering colleges affiliated to JNTU is English. The field study was carried out on engineering colleges located in Vijayawada, Visakhapatnam and Hyderabad, India.

\subsection{Participants}

The study was conducted on fifty two students pursuing first year engineering course of which twenty six students were girls and twenty six students were boys. The English teachers of the engineering colleges visited helped the researcher to identify students on the basis of the educational background. As the present study intends to probe the reading process of engineering students, we felt it was necessary to interview the students on the basis of their educational background. For this reason, students from English medium and regional medium (Telugu medium) background were interviewed by the researcher. These students were told that their responses would be kept confidential and used only for research purposes.

\subsection{Choice of Reading Passages}

A reading passage was used to elicit information on the reading process of engineering students. The results of our pilot study suggested that a text with a familiar vocabulary would make it very easy for the students to understand while too many technical terms would make it more difficult. Choosing too easy a text or too difficult a text may not give insights into the reading process. Hence, we decided to choose a semi-technical text. For this reason, an extract was taken from a journal of Information Technology. The selected reading passage was semi-technical. It was a combination of technical terms as well as words that are used in everyday life. It was felt that this kind of passage would give more insights as to how the students understand a semi-technical text. Since the engineering students often come across common English words as well as technical words in their academic courses and also in their future professional career, it was felt that this kind of passage would give insights of their reading strategies.

\subsection{Elements of Think-Aloud Verbal Reports}

Think-aloud verbal probe was used in our study to elicit students' responses on the reading passage. The theme given in the chosen reading passage (See Appendix) for the study was related to their academic topics. Think-aloud questions were used as a tool to elicit the students' mental processes. Each of the engineering student interviewed were given instructions to read the passage silently and then respond to the questions asked by the researcher. While responding to the think-aloud questions, students were allowed to look into the reading passage as and when they required. The responses of these students were recorded in audio cassettes. The recorded responses of the engineering students were transcribed for a better understanding of the verbal data. However, certain terms for data analysis have been interchangeably used. Following terms were used for data analysis. Some of the terms used have almost identical meaning in the analysis.

- Students means engineering students

- Teachers means English teachers

- Students and readers mean the same

- Strategies and reading strategies mean the same

- Reading passage and reading text mean the same

- Think-aloud probe/interview and verbal probe mean the same

- Think-aloud report and verbal report mean the same

Verbal questioning was intended to elicit information from the short-term memory of the engineering students. 
This was important because it is believed that the information available in the short-term memory can be accessed only for a certain period of time. Since the students were engaged in reading and their thought process could be active, the researcher felt that verbal reports elicited while reading could give detailed insights regarding the reading strategies of the engineering students. To elicit verbal responses for the reading passages, the researcher spent several minutes (ranging from 30 minutes to 120 minutes) with each student. The elicited verbal responses generated a large volume of data and so only relevant extracts on reading processes were presented in the data analysis section of this research paper. While analyzing the verbal report data of the students, the following research questions were considered:

1) What strategies do engineering students use while reading an academic related reading text?

2) How are students categorized?

3) Does the frequency of the strategy use vary from successful, partly successful and unsuccessful readers?

4) What are the problem areas of partly successful and unsuccessful readers?

A qualitative analysis of the collected data gives a better understanding of how engineering students apply strategies to construct the meaning of familiar and unfamiliar content.

\section{Data Analysis}

The reading passage used for obtaining data on mental processes of engineering students was selected from a Journal of Information Technology (see appendix A). An analysis of the verbal reports indicates that there was a variation in the reading processes of engineering students. Comprehension questions on reading passages were directed to the students in the verbal probe. On the basis of their response to the comprehension questions, students were categorized as successful, partly successful and unsuccessful readers. Students were categorized as successful if they could answer all the comprehension questions posed during the think-aloud verbal probe. If the students could answer some of the comprehension questions, they were categorized under partly successful readers while the students who were not able to answer any of the comprehension questions during the think-aloud verbal probe were categorised as unsuccessful readers. The researcher also directed verbal questions to get insights of how successful readers comprehend unfamiliar sentence structures and why partly successful and unsuccessful readers fail to comprehend a semi-technical text. The elicited verbal responses of all the 52 students were analyzed and presented in three categories. The three categories were based on successful use of strategies, partly successful use of strategies and unsuccessful use of strategies. The table below gives an overall categorization.

Table 1. Number of successful, partly successful and unsuccessful students

\begin{tabular}{llllll}
\hline Successful & & \multicolumn{2}{l}{ Partly Successful } & \multicolumn{2}{l}{ Unsuccessful } \\
\hline Male & Female & Male & Female & Male & Female \\
09 & 07 & 11 & 13 & 06 & 06 \\
\hline
\end{tabular}

\subsection{Successful Use of Reading Strategies}

Students are categorized as successful users of reading strategies on the basis of their responses to an academic related reading passage during the verbal interview. Students were categorized as successful users of reading strategies only if they could understand the reading passage completely. Successful students used reading strategies appropriately while reading an academic related text. These students were found to comprehend, analyze, monitor and interpret the information in the given reading passage. An analysis of verbal data of the successful readers indicates that sixteen (16) students are successful in understanding the meaning of an academic related text.

A short extract from the think aloud verbal probe of a successful reader

$R$ : Researcher, S: Student

Student 2: Male

$R$ : How could you grasp the meaning of all these words?

$S$ : (pause) first I looked at the entire concept as a whole,

$R:$ uh 
$S$ : So, once again the concept. Then I looked at the individual sentences. So, in individual sentences each sentence has its own idea. So, I get that idea. So, based on that idea I look for specific words. I don't know so those words (pause). Based on that idea I can begin to understand as I mentioned before. Suppose, I just grasp the idea, grasp the specific ideas, then I grasp the words itself.

$R$ : How could you grasp the ideas?

$S$ : Uh, I said looking at those main key ideas that (pause) and as I skim them certain ideas come to my head. certain like,

$R$ : What ideas come into your mind?

$S$ : Ah first I was thinking this was some kind, of you see, you are going to try to test me. So, I was trying to look for all the concepts. Then, I couldn't get it immediately because it was rather abstract. So, I looked at the whole thing as a whole (pause) then I jumped here and there. And then once I got. Like, Indian companies customers open source o.k. Then, I began to understand. This is about all these open source software and its impact on companies. Then I went line by line - line by line, each key word there each key word. Based on those key words, I found what image came to my head. So, internet based solutions. So, I began to think of what a internet explorer.

$R: \mathrm{Uh}$

$S$ : What a flash software they have on their, line by line, something came to my head (pause) on those somethings, I derive the meaning of the entire thing ...

$R$ : How did it come into your mind?

$S$ : It's an interesting question, I am not sure myself. I look at the word. Somebody says somebody's name, the face comes to my head. Like that, when I look at this word

$R: \mathrm{Uh}$

$S$ : On that concept, some image comes to my head. Not exactly the definition but some picture of something I have seen before.

$R: \mathrm{Uh}$

$S$ : Something that I have experienced that. That thought comes to my head ...

$R$ : How could you get those thoughts?

$S$ : Ah, actually my mind I must have linked these words to something. I have already experienced before

$R: \mathrm{Uh}$

$S$ : So, I have seen these words before-internet based solutions. I have seen that before. Indian companies, yes I have heard that before. So what I have heard before is coming by looking at those words.

$R$ : While reading this text what is going on in your mind?

$S$ : (pause) Ah (pause) .my mind ah (pause) when I am reading them, I am thinking about ah (pause) its I am thinking about (pause) as a side. I was just, when I was reading this, suddenly I just thought about Linux. So, as soon as I saw the word Linux I just paused for a few seconds and I thought about our Linux in schools, Linux $\mathrm{CD}$ that I have (pause) certain pauses in certain places where I have larger memory about them (pause).

(continued...)

\subsection{Partly Successful Use of Reading Strategies While Reading an Academic Related Text}

Students were categorized as partly successful readers because these students could understand only parts of the text. Partly successful students were not able to comprehend the complete meaning of the reading passage. Though these students could not understand the complete reading passage, they were found using reading strategies to comprehend the meaning of parts of the reading passage. Some students used a mixture of global, support and problem solving reading strategies while other students used only one set of strategies. However, the frequency of the use of reading strategies was less when compared to that of successful readers.

\section{A short extract from the think aloud verbal probe of a partly successful reader}

R: Researcher, S: Student

Student 9: Female

$R$ : How much of the text could you understand? 
$S$ : Not most of the text sir, some doubts are there like here in the sentence.

$R: \mathrm{Uh}$

$S$ : As a result they have come up with innovative shared competencies with their competitors. I didn't understand that sentence

$R: \mathrm{Uh}$

$S$ : And open source is a door opener which will reduce infrastructure.

$R: \mathrm{Uh}$

$S$ : And learning costs exponentially aid more focused development on many available platforms.

$R$ : Uh, why is it difficult to understand?

$S$ : Sir, it's not complex, the sentence is not complex sentence.

$R: \mathrm{Uh}$

$S:$ I couldn't understand what's the main essence of the sentence.

$R: \mathrm{Uh}$

$S:$ (pause) And what is the summary of this paragraph I don't understand sir

$R: \mathrm{Uh}$

$S:$ I think it is about developing the IT field

$R: \mathrm{Uh}$

$S$ : And what steps should be taken by India to develop, the IT (pause). In this sentence, Indian businesses need to realize that while an open business model may directly hit their bottom lines. It will, in the long term, lead to reduce costs, innovative development within the premises, steady growth returns along with wider demand for the core product. This sentence is too long sir. I couldn't understand.

$R$ : Why is it difficult to understand?

$S$ : (pause) Some terms are there, I don't know the meanings of those terms. That's why I can't understand this passage.

$R: \mathrm{Uh}$

$S$ : For example (pause), like monetize content leverage and monetize content. In this sentence particular Indian companies need to look towards integrating idea that sentence. Along with the ability to leverage and monetize content. I don't know the meaning of that.

(continued...)

\subsection{Unsuccessful Use of Reading Strategies}

The verbal reports of unsuccessful students indicate that 12 students could not understand an academic related text. Some of these students were found to be using some strategies though they were not successful in understanding the meaning of the reading passage. Two of the unsuccessful readers were able to identify few words because they had some background knowledge of these words.

A short extract from the think aloud verbal probe of an unsuccessful reader

R: Researcher, S: Student

Student 11: Male

$R$ : Could you understand the whole text?

$S$ : Some of the text is something complex sir.

$R$ : Uh, why is it complex?

$S$ : Because our communication skills are something low.

$R:$ Uh

$S$ : (pause)

$R$ : Could you understand any of these sentences?

$S$ : Yes sir 
$R$ : Which sentences could you understand?

$S$ : (pause) While Indian companies have strategic advantage in terms of global presence they need to leverage the open business model by forming intelligent partnerships and alliances to deliver collective innovative offerings.

$R$ : Uh, could you understand the sentence?

$S:$ No sir

$R$ : Uh, why is it difficult to understand?

$S$ : (pause) Because I don't know the meanings of some words and all this

$R$ : Uh, why do you think you don't know the meaning of some words?

$S$ : I am poor in English

$R: \mathrm{Uh}$

$S:$ (pause)

$R$ : In what sense you are poor in English?

$S$ : Knowing the dictionary meanings and all these

$R$ : Any other sentence you understood here?

$S$ : No sir

$R$ : Could you understand the meaning of the first sentence?

$S:$ (pause) No sir

$R$ : Any other sentences you understood here?

$S$ : No sir

$R$ : Why are these sentences difficult to understand?

$S$ : I don't know the meanings of the words which are present

$R: \mathrm{Uh}$

$S:$ (pause)

$R$ : While reading this text what is going on in your mind?

$S$ : After seeing the first sentence itself I became so nervous that

$R: \mathrm{Uh}$

$S$ : I could not get all the passage, I had got, And intention in my mind, that I may not be able to understand all these paragraph.

(continued...)

4.4 List of Strategies Unsuccessful Readers Failed to Use

A comparison of successful and unsuccessful readers' use of strategies reveals that unsuccessful readers failed to use most of the global, support, problem solving and other reading strategies while reading an academic related text. Global strategies that unsuccessful readers could not use include analyzing strategies, self-questioning strategies and organization of the text strategies. Support strategies that unsuccessful readers failed to use include strategies of relating information, strategies of linking ideas and summarizing strategies. Problem solving strategies that unsuccessful readers could not use include concentrating strategies, strategies of careful reading, visualizing strategies, pausing for comprehension strategies, strategies of guessing the meaning and strategies of dividing a word. In the category of other reading strategies, unsuccessful readers could not use lexical processing strategies, empathizing strategies, simplifying strategies, lexical categorizing strategies, translating strategies and literal meaning strategies. The unsuccessful readers could not understand the meaning because of the obstacles they encountered while reading. 
Table 2. Problem areas in reading comprehension

\begin{tabular}{lc}
\hline Problems in reading comprehension & No. of students \\
\hline Difficult sentence structures & 10 \\
Difficulty in translating & 03 \\
Unfamiliar concepts & 01 \\
Unfamiliar vocabulary & 07 \\
Inferencing problems & 12 \\
Lack of background knowledge & 06 \\
Disconnected sentences & 06 \\
Unfamiliar writing style & 02 \\
\hline
\end{tabular}

\subsection{Approach of Unsuccessful Readers towards Academic Related Text}

The attitude that unsuccessful readers bring to their reading also affects their comprehension. Following are some of the attitudes that affect their reading.

Table 3. Unsuccessful readers approach to an academic related text

\begin{tabular}{lc}
\hline Unsuccessful readers approach & No. of students \\
\hline Regional medium background & 07 \\
Poor proficiency in English language & 06 \\
Nervousness & 02 \\
Lack of foundation in English language skills & 02 \\
Frustration & 02 \\
Poor self perception & 02 \\
Dislike towards English language & 01 \\
\hline
\end{tabular}

4.6 Summary of the Use of Global, Support, Problem Solving and Other Reading Strategies While Reading an Academic Related Text

A summary of the reading strategy use of global, support, problem solving and other reading strategies used by successful, partly successful and unsuccessful readers is presented below:

Table 4. A summary of global, support, problem solving and other strategies used by all

\begin{tabular}{|c|c|c|c|c|c|}
\hline Type of readers & $\begin{array}{c}\text { No. of times } \\
\text { global strategies } \\
\text { used }\end{array}$ & $\begin{array}{c}\text { No. of times } \\
\text { support strategies } \\
\text { used }\end{array}$ & $\begin{array}{c}\text { No. of times problem } \\
\text { solving strategies } \\
\text { used }\end{array}$ & $\begin{array}{c}\text { No. of times } \\
\text { other strategies } \\
\text { used }\end{array}$ & Total \\
\hline $\begin{array}{l}\text { Successful } \\
\text { Students }\end{array}$ & 44 & 56 & 45 & 16 & 161 \\
\hline $\begin{array}{l}\text { Partly } \\
\text { successful } \\
\text { students }\end{array}$ & 20 & 43 & 21 & 12 & 96 \\
\hline $\begin{array}{l}\text { Unsuccessful } \\
\text { students }\end{array}$ & 01 & 02 & 01 & - & 04 \\
\hline
\end{tabular}

The above table indicates that the usage of reading strategies by successful readers while reading an academic related text is remarkably high when compared to partly successful and unsuccessful readers. The gap between the partly successful readers and unsuccessful readers is also quite wide. Unsuccessful readers used very few 
strategies when compared to successful and partly successful readers.

\section{Findings of the Study}

\subsection{New Learning Experience}

The think-aloud verbal probe used in this study elicited the mental processes of undergraduate engineering students while reading a semi-technical reading text. The response of the students revealed their cognitive processes and the steps they were taking to grasp the meaning while reading. The verbal questions were also directed on the kind of obstacles that students come across while reading and the immediate solutions they find to overcome the problems in comprehension. The research findings suggest that engineering students were not familiar with the verbal probe on their thinking process. Most of the students revealed that they found the verbal interview as a kind of brainstorming session while some students found the method of thinking on how and what they have read useful to improve their knowledge in what they are reading. Successful and some of the partly successful readers were able to give meanings of sentences but could not reveal the strategy used unless a directed question on their short term memory. This is probably because of not being conscious of the steps they take while reading an academic related text. These findings are significant in L2 learning situation because students are not aware of their own strategies and problems unless someone takes the initiative to make them reflect on the steps they take while reading.

\subsection{Success and Obstacles in Comprehension}

The feeling of success in a task is an important aspect that affects the reading process of the students. The findings of the verbal reports indicate that successful readers are motivated to approach a reading activity to gain knowledge. In quest to gain knowledge, these readers overcome the obstacles by consciously monitoring their reading process. The verbal reports of the successful readers in this study indicate that these students are in a relaxed mind and are confident towards the reading task. However, most of the partly successful readers and unsuccessful readers were nervous and expressed their lack of confidence in the use of English language. When these students came across obstacles while reading, they became nervous and lacked training to monitor their reading process.

\subsection{Meaning Is Primary in Comprehension}

The verbal reports of the successful and partly successful readers on thought processes indicate the use of cognitive strategies like grouping, imagery, elaboration, summarizing and translation. The findings of our research also indicate that getting the meaning is more important than identifying words because precise identification of all the words is not usually necessary for getting the meaning. The verbal reports of the successful readers and some of the partly successful readers indicate that readers could not get precise meaning of certain words. It is observed that these readers reread the sentences to make their thought processes clear. As they repeated the process of thinking and guessing while reading, these students could comprehend the meaning of the sentences that comprised of familiar and unfamiliar words. It is observed that not getting a precise meaning of an unfamiliar word did not affect their comprehension of a particular sentence.

\subsection{Importance of Textual Features}

Most of the successful and some of the partly successful readers were found activating their cognitive skills when they realized that they possess an inadequate knowledge of the target language. Most of the readers resorted to strategy use when they found difficult it to understand unfamiliar English vocabulary. Successful students were looking at the structure and organization of textual features like sentences, length of the text, word order, punctuations and the style of writing. Findings of the study reveal that understanding a text depends very much on text variables such as sentence structure and length, vocabulary intensity, number of new concepts introduced, the difficulty and novelty of the subject matter. Further, reader variables such as background knowledge, internal or non-visual information, reading proficiency and motivation also have an impact on the reader strategies while reading academic related text. These students could identify and use textual features to understand the meaning of the text. They were also able to construct an overall summary of the reading passage. Strategy of summarization indicates that successful readers read the text carefully and followed the content by identifying main points. They were able to categorize details and generalize the information presented in the text.

\subsection{Associating Sound with Cluster of Letters}

Successful readers were able to summarise and restate the main points and supporting details of the text verbally. These students used word structure clues like word order, prefixes, suffixes and syntactic clues to identify a new English vocabulary. Further, these students also identified new English words by associating its sounds with a cluster of letters which led to more rapid and efficient word identification. The findings of the verbal reports 
indicate that students used lexical processing strategies to identify key content words. Most of the successful readers were primarily relying on content words in the semi-technical text to construct the meaning of a sentence. The verbal reports indicate that students could process the information by grouping the content words and guessing semantic relationship between these words. Successful students used their knowledge of phrases to relate the information and make meaning. These students also relied on high frequency words to comprehend the text. The verbal reports of these students indicate that they used semantic and syntactic cues to relate the information. Their attention was on phrases rather than on letters of the alphabet. These students could make relations between concepts, ideas and sentences to relate the information.

\subsection{Strategies Used by Successful, Partly Successful and Unsuccessful Readers}

Findings of the verbal reports of the successful readers indicate that these readers related their personal experience and empathized with the information presented in the text. By relating their observations of the real world with the text, successful readers could grasp the meaning. While processing the information, a successful reader was found to be using simplification strategies like processing the meaning of words by using synonyms. The partly successful readers made limited use of cognitive skills whereas the unsuccessful readers even less. The verbal reports of the partly successful engineering students and unsuccessful students reveal that they read the words in isolation and do not make an attempt to understand the meaning of the complete sentence. These students try to grasp every word and thus end up spending too much time on a word without understanding its meaning. However, good readers made connections with their own experiences and related the new information to their prior knowledge. Unsuccessful and some of the partly successful readers were found ignoring punctuation and thus found the phrases and sentences as meaningless combination of words. While processing the information from academic related texts, successful readers were able to identify the devices which were used to appeal and influence their thinking. The verbal reports of successful readers indicate that they read extensively. Extensive reading broadens and increases vocabulary knowledge and this is important for effective communication and comprehension. Habit of reading extensively also gave them confidence while regular reading habits enhanced their concentration skills by expanding their attention span. Partly successful readers could understand parts of the text. However, English teachers need to give more training in the use of reading strategies to make these readers to move a step ahead in understanding the meaning and reach them to the level of successful readers. The problems of unsuccessful readers are enormous. Most of these readers lack proficiency in English language skills. Lack of basic knowledge in sentence structures and the usage of vocabulary in different contexts is an obstacle for the reading proficiency. Through extensive reading tasks, English teachers have to give language input and also train these students in the use of reading strategies. During the intensive reading activities, these unsuccessful readers have to be given individual attention in cognitive skills.

\section{Conclusion}

The findings of the study reveal that process oriented tasks will benefit the students. More research has to be carried out in the English classroom of engineering colleges by constructing reading tasks that give importance to reading process. A similar study can be conducted with the students from the same linguistic background to find out whether the reading process of the students varies or is similar when they are from same linguistic background. To get more insights on the reading process, classroom observation may be useful. A reading strategy questionnaire for English teachers probably can give more insights of English teachers' knowledge on the use of reading strategies. A study can be conducted by constructing reading tasks that promote reading process and test its effectiveness in English language classroom of engineering students.

\section{References}

Ajideh, P. (2003). Schema theory-based pre-reading tasks: A neglected essential in the ESL reading class. The Reading Matrix, 3(1), 1-14.

Alderson, J. C., \& Urquhart, A. H. (1984). Reading in a foreign language. London: Longman.

Ericsson, K., \& Simon, H. J. (1980). Verbal reports as data. Psychological Review, 87, 215-251.

Ericsson, K., \& Simon, H. J. (1993). Protocol analysis: Verbal reports as data. Cambridge, MA: MIT Press.

Garner, R. (1987). Metacognition and reading comprehension. Norwood, NJ: Ablex Publishing.

Hosenfeld, C. (1976). Learning about learning: Discovering our students' strategies. Foreign Language Annals, 9 , 117-129.

Learning English: A communicative approach. (2005). Edition prepared for Jawaharlal Nehru Technological 
University, Andhra Pradesh. Hyderabad: Orient Longman.

Mandler, J. M. (1998). Representation. In W. Damon, D. Kuhn, \& R. S. Siegler (Eds.), Handbook of child psychology: Cognition, perception and language (5th ed.). New York: John Wiley.

Mathew, N. G. (2009). A study of the English language reading strategies of engineering students in colleges affiliated to JNTU, Andhra Pradesh (Unpublished PhD dissertation, University of Hyderabad, Hyderabad).

Mokhtari, K., \& Reichard, C. (2002). Assesing students' metacogntive awareness of reading strategies inventory. Journal of Education Psychology, 94, 249-259.

Nielson, J. (1994). Estimating the number of subjects needed for a thinking aloud test. International Journal of Human-Computer Studies, 41(3), 385-397.

Ozek, Y., \& Civelek, M. (2006). A study on the use of cognitive reading strategies by ELT students. Asian EFL Journal: English Language Teaching and Research Articles, 14, 1.

Paris, S. G., \& Winograd, P. (1990). How metacognition can promote academic learning and instruction. In B. F. Jones, \& L. Idol (Eds.), Dimensions of thinking and cognitive instruction. Hillsdale, NJ: Erlbaum.

Schwartz, S. (1984). Measuring reading competence. New York: Plenum Press.

Singhal, M. (2001). Reading proficiency, reading strategies, metacognitive awareness and L2 readers. The Reading Matrix, 1,1 .

Someren, M. W. V., Yvonne, F. B., \& Jacobijn, A. C. S. (1994). The think-aloud method. A practical guide to modeling cognitive processes. London: Academic Press.

Taraban, R., Kerr, M., \& Rynearson, K. (2004). Analytic and pragmatic factors in college students' metacognitive reading strategies. Reading Psychology, 25, 67-81.

Thomposon, S. J. (2006). Using the think aloud method (Cognitive Labs) to evaluate test design for students with disabilities and English language learners. Technical Report 44. Minneapolis, MN: University of Minnesota, National Center on Educational Outcomes.

Vaezi, S. (2006). Theories of reading. BBC World Service, Bush House, Strand, London.

\section{Appendix}

Reading Passage (selected from the Journal Information Technology Today, Vol. 17, Issue 05, March 2007 Published by EFY - ISO 9001:2000 Certified)

The advent of Internet-based solutions for the workspace has spurred competition to a level where industry giants have been forced to sit up and take notice, and even open their gates to sustain themselves. As a result, they have come up with innovative, shared competencies with their competitors. While Indian companies have a strategic advantage in terms of global presence, they need to leverage the open business model by forming intelligent partnerships and alliances to deliver collective innovative offerings. Indian businesses need to realize that while an open business model may directly hit their bottom lines, it will, in the long term, lead to reduced costs in innovative development within the premises and steady growth returns along with wider demand for the core product. Indian companies need to look towards integrating ideas directly from customers, along with the ability to leverage and monetize content that customers may create. The formation of partnerships and alliances, and the creation of a "shared innovation" environment should also be encouraged as firms need to seek new sources of innovation within the country-in educational institutions or other niche technological companies. As a small aspect of the open business model, open source presents an ideal opportunity for India to deliver IT to her masses. Software such as Linux is freely available and is well supported. Open source is a door opener which will reduce infrastructure and learning costs exponentially and aid more focused development on many available platforms. The key is to educate the public on ways to control and customize these applications.

\section{Copyrights}

Copyright for this article is retained by the author(s), with first publication rights granted to the journal.

This is an open-access article distributed under the terms and conditions of the Creative Commons Attribution license (http://creativecommons.org/licenses/by/3.0/). 